\title{
Probiotics Improve Inflammation-Associated Sickness Behavior by Altering Communication between the Peripheral Immune System and the Brain
}

\author{
Charlotte D’Mello, ${ }^{1}$ Natalie Ronaghan, ${ }^{2}$ Raza Zaheer, ${ }^{2}$ Michael Dicay, ${ }^{2}$ Tai Le, ${ }^{1}$ Wallace K. MacNaughton, ${ }^{2}$ \\ Michael G. Surrette, ${ }^{3}$ and Mark G. Swain ${ }^{1}$ \\ ${ }^{1}$ Immunology Research Group and ${ }^{2}$ Gastrointestinal Research Group and Inflammation Research Network, Calvin, Phoebe and Joan Snyder Institute for \\ Chronic Diseases, Cumming School of Medicine, University of Calgary, Calgary, Alberta T2N 4N1, Canada, and ${ }^{3}$ Farncombe Family Digestive Health \\ Research Institute, McMaster University, Hamilton, Ontario L8S 4L8, Canada
}

Patients with systemic inflammatory diseases (e.g., rheumatoid arthritis, inflammatory bowel disease, chronic liver disease) commonly develop debilitating symptoms (i.e., sickness behaviors) that arise from changes in brain function. The microbiota-gut-brain axis alters brain function and probiotic ingestion can influence behavior. However, how probiotics do this remains unclear. We have previously described a novel periphery-to-brain communication pathway in the setting of peripheral organ inflammation whereby monocytes are recruited to the brain in response to systemic TNF- $\alpha$ signaling, leading to microglial activation and subsequently driving sickness behavior development. Therefore, we investigated whether probiotic ingestion (i.e., probiotic mixture VSL\#3) alters this periphery-tobrain communication pathway, thereby reducing subsequent sickness behavior development. Using a well characterized mouse model of liver inflammation, we now show that probiotic (VSL\#3) treatment attenuates sickness behavior development in mice with liver inflammation without affecting disease severity, gut microbiota composition, or gut permeability. Attenuation of sickness behavior development was associated with reductions in microglial activation and cerebral monocyte infiltration. These events were paralleled by changes in markers of systemic immune activation, including decreased circulating TNF- $\alpha$ levels. Our observations highlight a novel pathway through which probiotics mediate cerebral changes and alter behavior. These findings allow for the potential development of novel therapeutic interventions targeted at the gut microbiome to treat inflammation-associated sickness behaviors in patients with systemic inflammatory diseases.

Key words: cerebral intravital microscopy; microglia; monocytes; TNF-alpha

Significance Statement

This research shows that probiotics, when eaten, can improve the abnormal behaviors (including social withdrawal and immobility) that are commonly associated with inflammation. Probiotics are able to cause this effect within the body by changing how the immune system signals the brain to alter brain function. These findings broaden our understanding of how probiotics may beneficially affect brain function in the context of inflammation occurring within the body and may open potential new therapeutic alternatives for the treatment of these alterations in behavior that can greatly affect patient quality of life.

\section{Introduction}

Symptoms occurring during inflammatory diseases (e.g., bowel, joint, liver) greatly affect patient quality of life (QOL) (Dantzer et

\footnotetext{
Received Feb. 10, 2015; revised June 4, 2015; accepted June 23, 2015.

Author contributions: C.D., W.K.M., M.G.Su., and M.G.Sw. designed research; C.D., N.R., R.Z., M.D., and T.L. performed research; C.D., N.R., R.Z., W.K.M., and M.G.Su. analyzed data; C.D. and M.G.Sw. wrote the paper.

This work was supported by an Operating Grant and Team Grant (Chronic Inflammation Initiative) awarded by the Canadian Institutes of Health Research (M.G.Sw. as principal investigator, the Cal Wenzel Family Foundation Chair in Hepatology (M.G.Sw.), and the Live Cell Imaging Facility funded by an equipment and infrastructure grant from Canadian Foundation Innovation and Alberta Science and Research Authority. C.D. was a doctoral candidate supported by a Canadian Institutes of Health Research Frederick Banting doctoral award. M.G.Sw. is a Professor of
}

al., 2008; D'Mello and Swain, 2014). However, how peripheral inflammation leads to changes in brain function and altered behavior are poorly understood. Disease-associated changes in behavior have been modeled in animals and are defined as sickness behaviors (Bluthé et al., 2006). Previously, using a model of experimentally induced liver inflammation, we identified periph-

Medicine and holds the Cal Wenzel Family Foundation Chair in Hepatology. We thank Claudio De Simone (University of L'Aquila, L'Aquila, Italy) for providing us with VSL\#3, Divine Tanyingoh (University of Calgary) for statistical assistance, ina Colarusso and Kasia Stevens (University of Calgary Live Cell Imaging Facility) for microscope training and technical advice related to imaging, and Laurie Kennedy and Yiping Liu (University of Calgary Flow Cytometry Core Facility) for assistance with flow cytometry. 
eral TNF- $\alpha$-induced microglia activation and recruitment of monocytes to the brain as critical steps in the development of inflammation-associated sickness behaviors (D'Mello et al., 2013). Moreover, the clinical relevance of these findings is supported by the widely reported effect of anti-TNF- $\alpha$ therapies in improving sickness behaviors in patients suffering from a number of inflammatory diseases, often well before changes in tissue inflammation are observed (Lichtenstein et al., 2002; Strand et al., 2011; Weiler-Normann et al., 2013).

The influence of gut microbiota on brain function and behavior are increasingly recognized (De Palma et al., 2014). Probiotics are live microorganisms that are commonly ingested to provide health benefits. Interestingly, probiotic consumption has also been shown to alter brain function and behavior in healthy humans. Specifically, probiotic ingestion can have beneficial effects on mood and cognition (Messaoudi et al., 2011) and has also been associated with changes in neural activity in brain regions involved in emotional processing (Tillisch et al., 2013). In addition, probiotic consumption has been associated with changes in brain function in patients with a variety of medical conditions including chronic fatigue (Ahmed et al., 2009), irritable bowel syndrome (O'Mahony et al., 2005), and in patients with hepatic encephalopathy (Mittal et al., 2011; Lunia et al., 2014). The mechanism whereby probiotic ingestion leads to changes in brain function and behavior remain unclear, but have been linked to changes in gut flora (although not routinely observed), changes in gut permeability, and shifts in systemic immunity with decreased production of proinflammatory cytokines, including TNF- $\alpha$ (O'Mahony et al., 2005; Hemarajata and Versalovic, 2013).

VSL\#3 is a probiotic mixture that has been widely used clinically, mainly to treat mild to moderately active inflammatory bowel disease (Hungin et al., 2013). VSL\#3 also appears to be beneficial in some patients with advanced liver disease because VSL\#3 ingestion decreased plasma levels of proinflammatory cytokines (e.g., TNF- $\alpha$ ) (Loguercio et al., 2005), improved QOL (Mittal et al., 2011), and reduced hospitalizations for hepatic encephalopathy (Dhiman et al., 2014). Furthermore, VSL\#3 has recently been linked to an effect on brain function in that VSL\#3 ingestion altered brain gene expression (Distrutti et al., 2014). Therefore, we administered VSL\#3 to mice with liver inflammation to determine its effects on sickness behavior development and to determine how oral VSL\#3 administration leads to changes within the brain. Our findings highlight a novel pathway whereby probiotic administration mediates improvement in inflammation-associated sickness behaviors by altering systemic immunity, decreasing microglial activation, and reducing recruitment of TNF- $\alpha$-secreting monocytes to the brain.

\section{Materials and Methods}

Murine model of peripheral inflammation. Mice (all on C57BL/6 genetic background, males, 6-8 weeks old) were used for all studies (The Jackson Laboratory) and were maintained in a pathogen-free facility. All procedures conformed to guidelines established by Canadian Council on Animal Care. For these experiments, we used the well characterized model of liver inflammation due to bile duct ligation (BDL) as described previously (Kerfoot et al., 2006; Nguyen et al., 2008; D’Mello et al., 2009; Nguyen et al., 2012; D’Mello et al., 2013); sham ligated mice served as

The authors declare no competing financial interests.

Correspondence should be addressed to Dr. Mark G. Swain, University of Calgary, 3280 Hospital Dr. NW, Calgary AB T2N 4N1, Canada. E-mail: swain@ucalgary.ca.

DOI:10.1523/JNEUROSCI.0575-15.2015

Copyright $\odot 2015$ the authors $\quad 0270-6474 / 15 / 3510822-10 \$ 15.00 / 0$ controls. This model is associated with elevated circulating cytokine levels (e.g., TNF- $\alpha$, IL-6) and the reproducible development of sickness behaviors (D'Mello et al., 2009; D’Mello et al., 2013). Systemic anticytokine treatment (e.g., anti-TNF- $\alpha$ ) in this model improves sickness behaviors, mimicking findings from clinical settings in patients with inflammatory diseases (Strand et al., 2012). All experiments were performed $10 \mathrm{~d}$ after surgery. Mice were gavaged orally with a VSL\#3 probiotic mixture containing eight live, freeze-dried bacterial species: Streptococcus salivarius subsp., thermophilis, Bifidobacterium (B. breve, $B$. infanti, B. longum), Lactobacillus acidophilis, L. planarum, L. casei, and $L$. delbrueeki subsp. Bulgaricus; 1.7 billion bacteria, or placebo (both kindly provided by Prof. C. De Simone, VSL Pharmaceuticals, Rome, Italy) in saline vehicle $(0.1 \mathrm{ml})$ for $10 \mathrm{~d}$ before surgery. Mice were then randomly separated into BDL and sham surgery groups and VSL\#3 or vehicle treatment continued until day 10 after surgery, when tissues were harvested or behavioral studies performed. Changes in liver injury severity were determined by measuring serum alanine aminotransferase (ALT) and total bilirubin levels and by histological changes. ALT and bilirubin levels were measured in a commercial laboratory (Calgary Laboratory Services). Histological assessment of liver inflammation and fibrosis were done using H\&E and sirius red-fast green (for collagen) stains, respectively.

For studies examining the potential effects of TNF- $\alpha$ inhibition, mice were administered etanercept (Enbrel; Amgen; $3 \mathrm{mg} / \mathrm{kg}$ subcutaneously; dose previously shown to block TNF- $\alpha$ activity) (O'Connor et al., 2009) or saline vehicle daily from day 2 post-BDL to day 10 post-BDL.

Body weight and sickness behavior assessment. Mice were weighed daily in the morning. The assessment of "social exploratory" behavior in rodents is a highly reproducible and robust behavioral paradigm used to quantify sickness behavior (Bluthé et al., 2006). This paradigm examines the motivation, interest, and ability of an adult mouse to engage in social behaviors (Bluthé et al., 2006), all of which are adversely affected by peripheral organ inflammation in humans and in experimental models (D'Mello et al., 2013; D'Mello and Swain, 2014). The time spent by an adult mouse engaging in social investigative behavior toward a juvenile mouse, which has been introduced into the adult mouse home cage, compared with time spent in nonsocial behavior and the time spent remaining immobile, were recorded as described previously (D'Mello et al., 2013).

Assessment of gut permeability. The intestinal tract from the stomach to the rectum was removed from the mice and the most distal portion of the colon was removed and snap-frozen for myeloperoxidase (MPO, a marker of neutrophilic inflammation) analysis. The next $1.5 \mathrm{~cm}$ of the colon and a $1.5 \mathrm{~cm}$ section from the center of the small intestine were dissected for Ussing chamber (Physiologic Instruments) analysis. Tissue in Ussing chambers was bathed in Krebs buffer containing the following (in mM): $115 \mathrm{NaCl}, 2 \mathrm{KH}_{2} \mathrm{PO}_{4}, 2.4 \mathrm{MgCl}_{2} 6 \mathrm{H}_{2} \mathrm{O}, 25 \mathrm{NaHCO}_{3}, 8 \mathrm{KCl}$, and $1.25 \mathrm{CaCl}_{2}$ with $10 \mathrm{~mm}$ mannitol (mucosal) or glucose (serosal) and maintained at $37^{\circ} \mathrm{C}$ and bubbled with $95 \% \mathrm{O}_{2}-5 \% \mathrm{CO}_{2}$. Fluoresceinisothiocyanate (FITC) dextran ( $0.5 \mathrm{~mm}$; Sigma-Aldrich) was added to the mucosal compartment and the serosal side was sampled every $20 \mathrm{~min}$ for $80 \mathrm{~min}$ total (colon) or every $10 \mathrm{~min}$ for $60 \mathrm{~min}$ total (small intestine). FITC fluorescence was measured using a Victor X4 2013 Multilabel Reader (PerkinElmer) (Wang et al., 2014).

Microbiome analysis. DNA extraction, 16sRNA amplification, and sequence processing analysis were done as described previously (Whelan et al., 2014).

Intravital microscopy of cerebral vasculature. Intravital microscopy of cerebral vasculature was conducted as described previously (Kerfoot et al., 2006; D’Mello et al., 2013). Briefly, under ketamine (100 mg/kg)/ xylazine $(10 \mathrm{mg} / \mathrm{kg})$ anesthesia, a craniotomy was performed and the dura mater removed to expose the underlying pial vasculature. The mouse was maintained at $37^{\circ} \mathrm{C}$ and the tail vein cannulated for administration of dyes and antibodies. Rhodamine- $6 \mathrm{G}$ dye $(0.3 \mathrm{mg} / \mathrm{kg}$; SigmaAldrich) was used to label all circulating leukocytes. Cerebral endothelial cells (CECs) were labeled with a FITC/allophycocyanin-labeled antiCD31 antibody ( $2 \mu \mathrm{g} /$ mouse, i.v.; eBioscience). Five vessels of 30 $-70 \mu \mathrm{m}$ diameter were recorded using a video recorder for $1 \mathrm{~min}$ and data were averaged. Rolling leukocytes were defined as cells that moved at a velocity less than that of an erythrocyte past a given point within a $100 \mu \mathrm{m}$ vessel 
segment. Adherent leukocytes were defined as cells that remained stationary for $30 \mathrm{~s}$ or longer within a $100 \mu \mathrm{m}$ vessel segment.

Leukocyte-CEC interactions were imaged using a Quorum WaveFX spinning disk confocal microscope driven by Volocity 6.1 acquisition software (PerkinElmer). Labeled cells were imaged using 491, 561, or 635 $\mathrm{nm}$ laser excitation and visualized with the appropriate long-pass filters using a $10 \times / 0.33$ numerical aperture air objective. A $512 \times 512$ pixel back-thinned EMCCD camera (Model C9100-13; Hamamatsu) was used for fluorescence detection.

Assessment of probiotic-related changes in systemic immunity. Blood was collected by cardiac puncture into tubes containing EDTA and stored at $-80^{\circ} \mathrm{C}$. To determine potential VSL\#3-related changes in systemic immunity, serum cytokine and chemokine levels were measured by Luminex (Millipore MCYTOMAG-70K mouse cytokine 32-plex; Eve Technologies).

Assessment of cerebral monocyte infiltration and microglia activation. Brain mononuclear cells (i.e., infiltrating monocytes and microglia) were isolated from cerebral cortices using our previously described protocols and characterized by flow cytometry (D'Mello et al., 2009; D'Mello et al., 2013). To distinguish between resting/activated microglia and cerebral infiltrating monocytes, we used the expression of CD11b coupled with the differential expression of CD45 antigen, as determined by flow cytometry. Based on these criteria, resting and activated microglia are defined as $\mathrm{CD} 45^{\text {low }} \mathrm{CD} 11 \mathrm{~b}^{+}$and $\mathrm{CD} 45^{\text {intermediate }} \mathrm{CD} 11 \mathrm{~b}^{+}$cells, respectively; infiltrating monocytes are defined as $\mathrm{CD} 45^{\text {high }} \mathrm{CD} 11 \mathrm{~b}^{+}$cells (Sedgwick et al., 1991). Intracellular TNF- $\alpha$ production by cerebral infiltrating monocytes and microglia was examined as described previously using flow cytometry with a PE-labeled anti-TNF- $\alpha$ antibody (D'Mello et al., 2013). All antibodies were from eBioscience. Immunohistochemitsry for Iba-1 (Wako Chemicals) was performed as described previously (D’Mello et al., 2013).

Statistical analysis. Data (mean \pm SEM) were analyzed using SPSS Statistics 22 software. For comparison between two means, Student's unpaired $t$ test was used. For comparison of four groups, a two-way (surgery $\times$ treatment) ANOVA was used and when the interaction was significant, a Tukey-Kramer post hoc pairwise multiple-comparison procedure was used. $p<0.05$ was considered significant.

\section{Results}

Characterization of liver inflammation and sickness behavior development in BDL mice

BDL mice showed: (1) an $~ 31$-fold increase in serum ALT levels (surgery effect: $F=69.47, p<0.0001$ ), (2) an $\sim 189$-fold increase in serum bilirubin levels (surgery effect: $F=39.98, p<0.0001$ ), (3) a decrease in body weight (surgery effect: $F=282.03, p<$ 0.0001 ), and (4) a mild increase in liver fibrosis compared with sham controls (Fig. 1A-D). There was no evidence of colonic inflammation (as measured by determining bowel MPO levels; data not shown) or significant changes in colonic or small bowel permeability in BDL compared with sham mice (Fig. 1E). As previously reported using a social investigation behavioral paradigm to delineate sickness behavior development (D'Mello et al., 2009; D’Mello et al., 2013), BDL mice reproducibly developed overt sickness behaviors, spending significantly less time engaging in social investigative behavior (i.e., interacting with the juvenile mouse; surgery effect: $F=72.17, p<0.0001)$ and more time in noninvestigative behaviors (e.g., grooming, being immobile; surgery effect: $F=40.01, p<0.0001)$ compared with sham controls (Fig. 2).

\section{Impact of oral VSL\#3 administration in BDL mice}

We next determined the effects of VSL\#3 treatment upon liver injury severity, bowel permeability, gut microbiota, and sickness behavior development.
Effect on markers of liver injury and bowel permeability

VSL\#3 treatment had no discernible hepatic effects or effects on bowel permeability measures in sham mice. Moreover, in BDL mice, VSL\#3 treatment did not alter serum ALT or bilirubin levels or body weight and no changes in liver inflammation or fibrosis were detected histologically (Fig. $1 A-D$ ). Furthermore, VSL\#3 treatment did not alter colonic or small bowel permeability (Fig. $1 E$ ) or colonic MPO levels in BDL mice (data not shown).

\section{Effect of VSL\#3 treatment on gut microbiota}

To investigate the impact of VSL\#3 treatment on the gut microbiota, 16S rRNA gene profiling was performed on fecal pellets from each mouse. Paired-end Illumina sequencing of the V3 region was performed and the data processed as described previously (Whelan et al., 2014). For the 36 samples, a total of $4,957,160$ sequence reads were used in the analysis (the minimum and maximum number of reads per sample was 66,131 and 188,558 , respectively; Table 1) that clustered into 1657 operational taxonomic units. There was no difference in $\alpha$-diversity between the four groups of mice, indicating no major disruption to the gut microbiome by the surgical procedure or probiotic treatment (Fig. $3 A$, Table 1 ). When examined using $\beta$-diversity metrics, the samples separated based on the presence of liver inflammation (i.e., sham vs BDL), but not probiotic intervention, using Bray-Curtis (Fig. 3B) or weighted Unifrac analysis (Table 1). The distribution of taxa between the four groups were similar, although the Bacteroidetes and Firmicutes were increased and reduced, respectively, in the BDL group compared with sham controls (Fig. 3C,D).

\section{Effect of VSL\#3 on sickness behavior development}

VSL\#3 treatment did not alter behavior in sham mice (Fig. 2). In contrast, BDL mice treated with VSL\#3 showed a significant improvement in sickness behavior development. This improvement in sickness behavior was indicated by a significant increase in the time that VSL\#3-treated BDL mice spent in social investigation (surgery $\times$ treatment: $F=6.37, p=0.016$ ) and a significant decrease in time spent remaining immobile (surgery $\times$ treatment: $F=5.26, p=0.029)$ compared with BDL mice treated with placebo (Fig. 2).

\section{VSL\#3 treatment alters systemic immunity and attenuates inflammatory monocyte recruitment to the brain in BDL mice}

We have shown previously that peripheral monocytes are activated, produce TNF- $\alpha$, and specifically transmigrate into the brains of BDL compared with sham control mice. Moreover, cerebral monocyte recruitment in BDL mice is critical for sickness behavior development (D'Mello et al., 2009). Microglia are activated before monocyte infiltration into the brains of BDL mice and produce the potent monocyte chemoattractant MCP1/CCL2 (D’Mello et al., 2009). Moreover, peripheral TNF- $\alpha$ signaling plays a key role in mediating microglial activation and cerebral monocyte recruitment in this setting. Therefore, we determined whether VSL\#3 treatment attenuates sickness behavior development in BDL mice by altering this pathway. Specifically, we delineated whether the improvement in sickness behaviors seen with VSL\#3 treatment in BDL mice was paralleled by alterations in peripheral TNF- $\alpha$ production, microglial activation, and/or cerebral monocyte infiltration.

VSL\#3 treatment alters systemic immunity in BDL mice To determine whether VSL\#3 treatment alters systemic immunity, we screened peripheral blood samples obtained from 
A

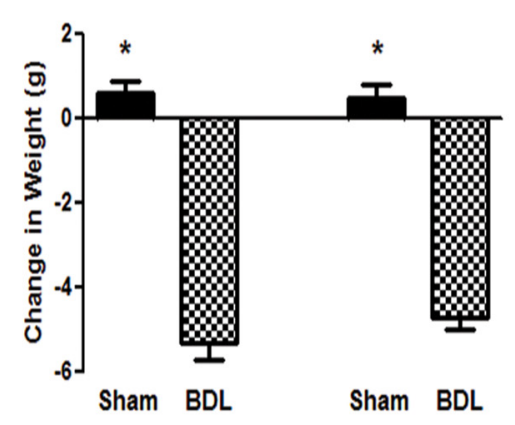

B

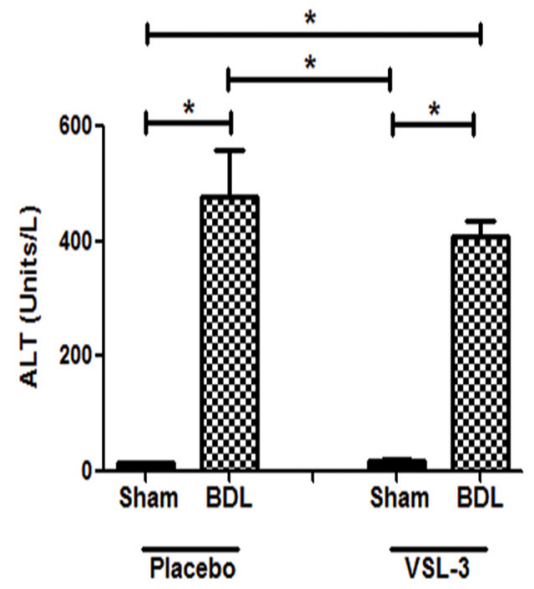

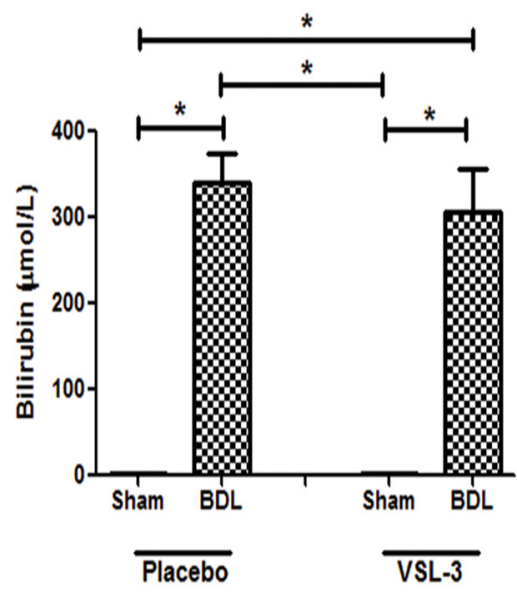

C
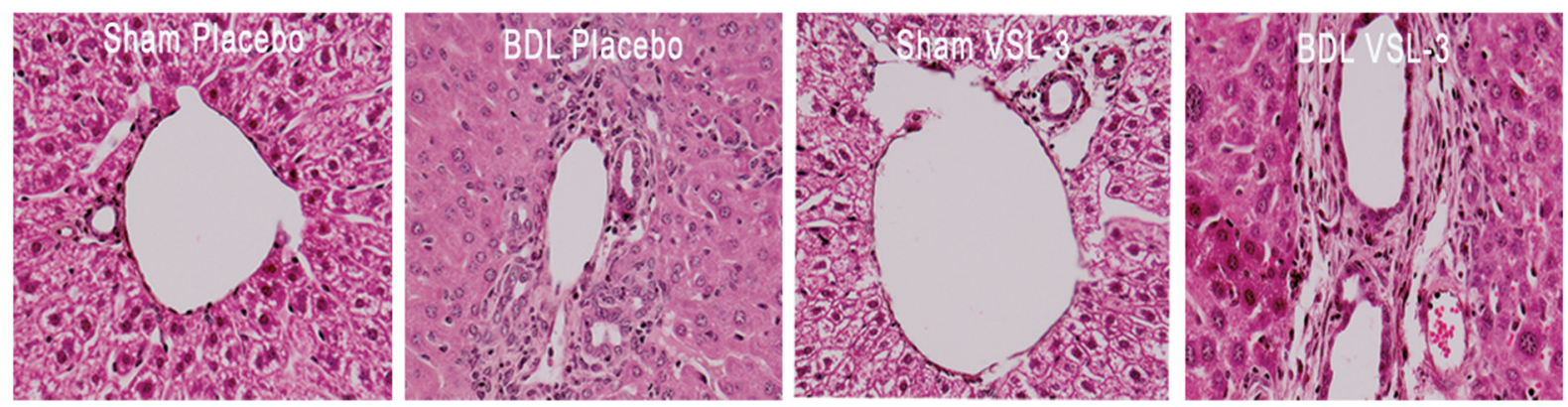

D
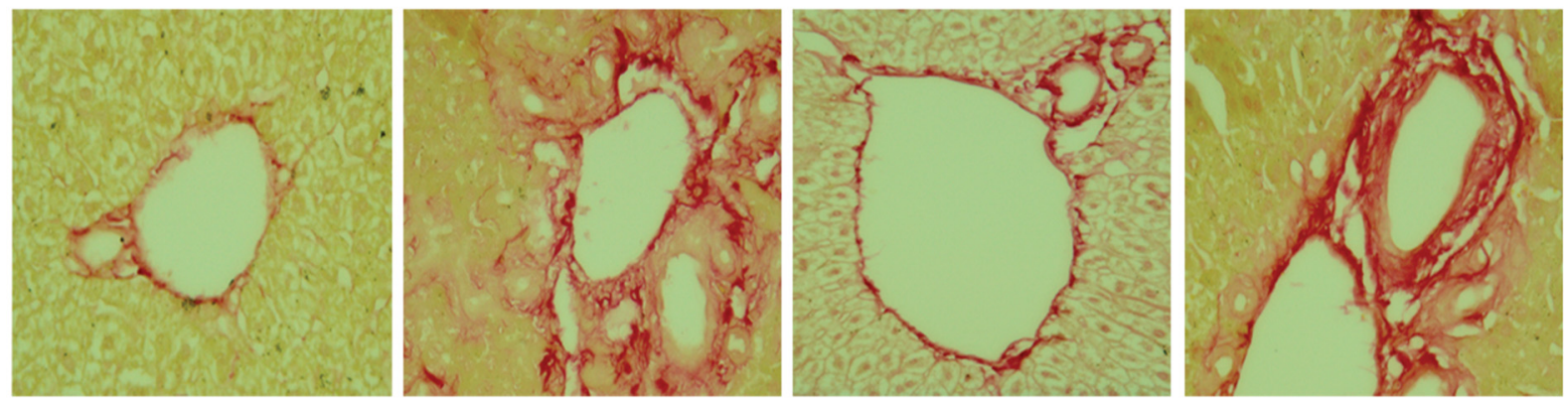

$\mathbf{E}$
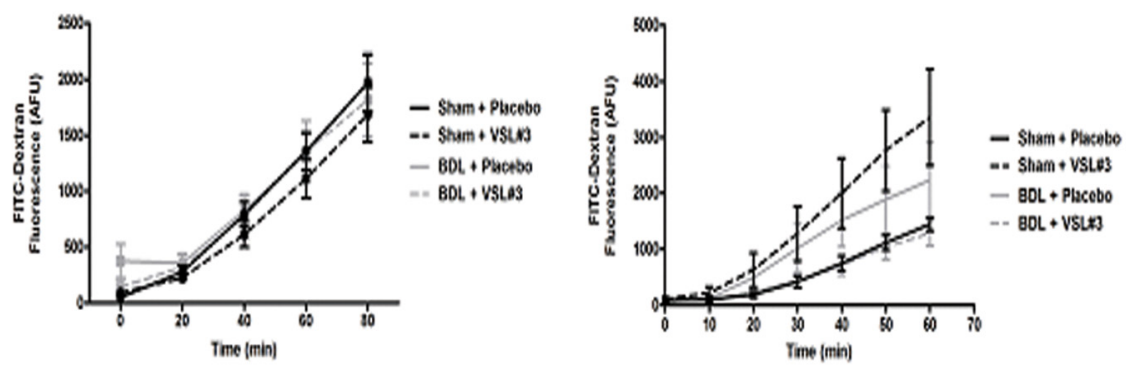

Figure 1. VSL\#3 treatment does not alter markers of liver injury or gut permeability. $\boldsymbol{A}, \boldsymbol{B}$, Change in body weight $(\boldsymbol{A})$ and ALT and bilirubin values ( $\boldsymbol{B})$ for placebo- and VSL\#3-treated sham and $\mathrm{BDL}$ mice. All data represented as mean $\pm \mathrm{SEM}, n=5-10 /$ group, ${ }^{*} p<0.05$ vs sham mice. Representative images of liver sections depicting histology (H\&E; $C$ ) and Sirius red-fast green staining (for collagen; $\boldsymbol{D}$ ) in placebo- and VSL\#3-treated sham and BDL mice. $\boldsymbol{E}$, No change in colonic or small intestinal barrier function in BDL- or VSL\#3-treated BDL mice. FITC- dextran flux (arbitrary fluorescence units) was assessed in colonic $(\boldsymbol{A}, n=6-10)$ and small intestinal $(\boldsymbol{B}, n=4-7)$ tissue mounted in Ussing chambers from sham and BDL mice. No significant differences in macromolecular flux were observed.

placebo- and VSL\#3-treated mice for a number of cytokines and chemokines using a Luminex assay (Millipore Mouse Cytokine 32-plex kit). Both placebo and VSL\#3 treated groups of BDL mice exhibited significant increases in circulating levels of a number of cytokines/chemokines compared with sham mice, including eotaxin (surgery effect: $F=16.61, p<0.001$ ), IL-6 (surgery effect:
$F=24.52, p<0.001)$, CXCL10/IP-10 (surgery effect: $F=25.17$, $p<0.001$ ), CXCL9/MIG (surgery effect: $F=9.8, p=0.004$ ), and CXCL1/KC (surgery effect: $F=36.1, p<0.001$ ); however, the elevated levels of these cytokines/chemokines in BDL mice were not altered by VSL\#3 treatment (Table 2) Plasma levels of the cytokines TNF- $\alpha$ and granulocyte-colony stimulating factor 

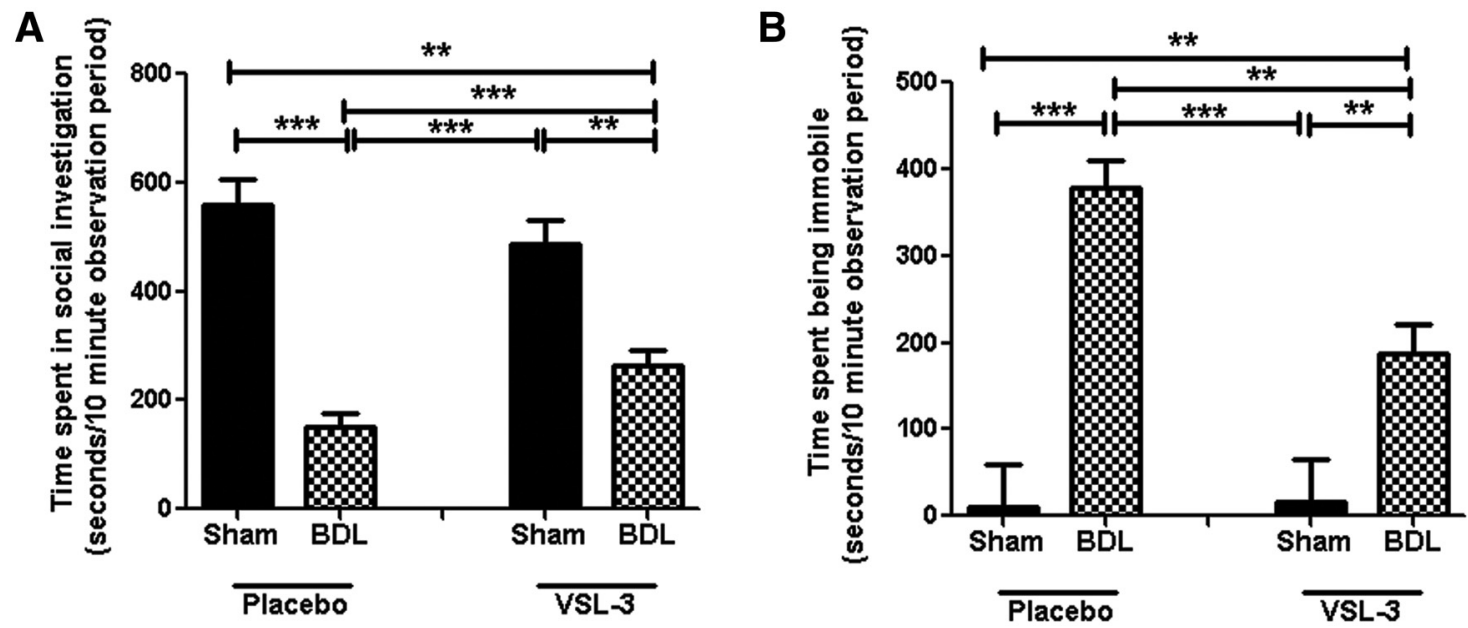

Figure 2. VSL\#3 treatment improves sickness behavior in BDL mice. Total time in seconds an adult test mouse spent in social exploration $(\boldsymbol{A})$ or remaining immobile $(\boldsymbol{B})$ during a 10 min observation period; $n=5-14 /$ group, ${ }^{*} p<0.05,{ }^{* *} p<0.01,{ }^{* *} p<0.0001$. All data are represented as mean \pm SEM.

Table 1. Summary of $\alpha$ - and $\beta$-diversity metrics for all samples

\begin{tabular}{|c|c|c|c|c|c|c|c|c|c|c|}
\hline \multirow[b]{2}{*}{ Sample } & \multirow[b]{2}{*}{ Group } & \multirow[b]{2}{*}{ Reads } & \multicolumn{2}{|c|}{$\alpha$-Diversity } & \multicolumn{3}{|l|}{ Bray-Curtis } & \multicolumn{3}{|c|}{ Weighted Unifrac } \\
\hline & & & chao1 & Shannon & PCoA1 (23.5) & PCoA2 (14.2) & $\mathrm{PCOA3}(11.0)$ & PCoA1 (33.3) & PCoA2 (16.1) & PCoA3 (9.8) \\
\hline Swain1 & A & 153147 & 377.9 & 4.03 & -0.0185 & 0.1298 & -0.0934 & -0.2424 & -0.0288 & -0.0654 \\
\hline Swain 10 & A & 183226 & 581.5 & 4.52 & -0.1001 & 0.1021 & -0.0381 & -0.0906 & -0.0769 & 0.0799 \\
\hline Swain14 & A & 174603 & 382.5 & 3.86 & -0.0143 & 0.1516 & -0.0594 & -0.2610 & -0.0144 & 0.0277 \\
\hline Swain15 & A & 147902 & 407.2 & 3.72 & -0.0068 & 0.1597 & -0.1714 & -0.2275 & -0.0479 & 0.1741 \\
\hline Swain19 & A & 146159 & 363.7 & 3.81 & -0.0242 & 0.1359 & -0.1792 & -0.2115 & -0.0602 & 0.2139 \\
\hline Swain2 & A & 166995 & 414.7 & 4.35 & -0.2497 & -0.0248 & -0.0367 & -0.0233 & -0.1788 & -0.0981 \\
\hline Swain20 & A & 145865 & 593.6 & 4.57 & -0.2757 & -0.0830 & 0.0047 & 0.0836 & -0.1842 & 0.1266 \\
\hline Swain21 & B & 133292 & 466.8 & 4.34 & -0.0159 & -0.0425 & -0.1368 & -0.0169 & -0.0405 & -0.0480 \\
\hline Swain22 & B & 90725 & 412.5 & 4.10 & -0.0402 & -0.1817 & -0.1927 & 0.2195 & -0.1235 & -0.0403 \\
\hline Swain26 & B & 66131 & 356.7 & 3.82 & -0.1583 & 0.1165 & -0.0742 & -0.1868 & -0.0441 & -0.0256 \\
\hline Swain27 & B & 89916 & 348.3 & 3.89 & 0.1164 & 0.0718 & -0.0041 & -0.1523 & 0.0840 & -0.0733 \\
\hline Swain5 & B & 134335 & 419.2 & 4.09 & 0.0039 & 0.2088 & 0.0892 & -0.2264 & -0.0024 & -0.0360 \\
\hline Swain6 & B & 171262 & 383.6 & 3.90 & -0.0485 & 0.2095 & 0.0475 & -0.2574 & -0.0659 & -0.0234 \\
\hline Swain9 & B & 171570 & 554.7 & 4.19 & -0.2596 & 0.0116 & 0.0824 & 0.0572 & -0.1428 & 0.0746 \\
\hline Swain13 & C & 159246 & 395.8 & 3.94 & 0.1568 & -0.1971 & -0.1076 & 0.3516 & 0.0396 & 0.0829 \\
\hline Swain16 & C & 145630 & 471.9 & 4.21 & 0.1543 & -0.0466 & 0.0669 & 0.1090 & 0.0816 & -0.1050 \\
\hline Swain17 & C & 149986 & 376.1 & 3.87 & 0.2273 & -0.0699 & 0.0009 & 0.1140 & 0.2157 & 0.1061 \\
\hline Swain24 & C & 92301 & 400.3 & 3.70 & 0.0848 & 0.0555 & -0.0889 & -0.0965 & 0.0992 & 0.0903 \\
\hline Swain25 & C & 99272 & 334.8 & 3.54 & 0.1695 & 0.0492 & -0.0305 & -0.0722 & 0.1852 & 0.1218 \\
\hline Swain3 & C & 160756 & 497.3 & 4.39 & 0.0850 & 0.0194 & -0.0139 & -0.0458 & 0.0655 & -0.0869 \\
\hline Swain30 & C & 121335 & 403.3 & 4.35 & 0.1048 & -0.0828 & 0.0007 & 0.0639 & 0.0739 & -0.0944 \\
\hline Swain31 & C & 77896 & 360.4 & 4.20 & 0.0350 & -0.2315 & -0.0014 & 0.2369 & 0.0288 & -0.0272 \\
\hline Swain33 & C & 108864 & 178.8 & 2.77 & 0.1959 & 0.0913 & -0.0900 & -0.2096 & 0.1557 & 0.0452 \\
\hline Swain34 & C & 102766 & 365.2 & 4.25 & -0.3673 & -0.1081 & 0.0699 & 0.0325 & -0.1935 & -0.0607 \\
\hline Swain35 & C & 127051 & 315.5 & 3.97 & 0.1263 & -0.0731 & 0.0639 & 0.0184 & 0.1094 & -0.0883 \\
\hline Swain36 & C & 130537 & 283.6 & 3.31 & 0.0846 & -0.2474 & -0.1585 & 0.4277 & -0.0888 & 0.2696 \\
\hline Swain4 & C & 159247 & 482.1 & 4.27 & 0.0124 & 0.0239 & -0.0498 & 0.0225 & -0.0451 & -0.1236 \\
\hline Swain11 & D & 185944 & 458.8 & 3.97 & -0.0903 & 0.1364 & 0.1502 & -0.0774 & -0.0653 & -0.0005 \\
\hline Swain12 & D & 163919 & 619.4 & 4.70 & 0.0107 & -0.0961 & 0.2524 & 0.2388 & 0.0304 & 0.0102 \\
\hline Swain18 & D & 155890 & 312.0 & 3.55 & 0.2315 & 0.0488 & 0.0631 & -0.0810 & 0.2231 & -0.0006 \\
\hline Swain23 & D & 123825 & 315.3 & 3.31 & 0.2291 & -0.1595 & 0.1857 & 0.2914 & 0.2187 & -0.0888 \\
\hline Swain28 & D & 122809 & 463.8 & 4.60 & -0.3888 & -0.1587 & -0.0842 & 0.1129 & -0.2688 & -0.0527 \\
\hline Swain29 & D & 119788 & 388.6 & 4.47 & -0.2484 & -0.0731 & 0.1704 & 0.1149 & -0.1917 & -0.1646 \\
\hline Swain32 & D & 124881 & 325.5 & 3.75 & 0.2103 & -0.0785 & 0.0169 & 0.1200 & 0.1483 & -0.0464 \\
\hline Swain7 & D & 161531 & 335.7 & 3.67 & 0.0349 & 0.2472 & 0.0817 & -0.2313 & -0.0034 & -0.0053 \\
\hline Swain8 & D & 188558 & 474.2 & 4.13 & 0.0331 & -0.0145 & 0.2643 & 0.0953 & 0.1078 & -0.0676 \\
\hline
\end{tabular}

Group A, Sham placebo; Group B, sham VSL-3; Group C, BDL placebo; Group D, BDL VSL\#3.

(G-CSF) were also elevated in BDL versus sham mice, but, in contrast to the other groups of chemokines/cytokines listed in Table 2, plasma levels of both TNF- $\alpha$ and G-CSF were significantly altered by VSL\#3 treatment. Specifically, VSL\#3 treatment of BDL mice significantly increased plasma G-CSF levels (sur- gery $\times$ treatment: $F=6.3, p=0.016)$ and decreased plasma TNF- $\alpha$ levels (surgery $\times$ treatment: $F=9.81, p=0.005$ ) compared with placebo-treated BDL mice (Fig. 4).

To determine whether VSL\#3 was potentially mediating its effects on sickness behavior in BDL mice by inhibiting TNF- $\alpha$ 
A

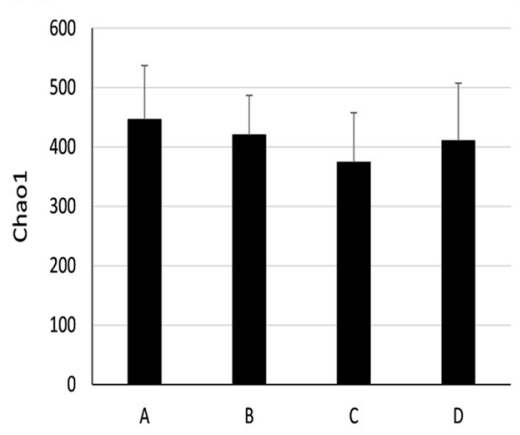

B

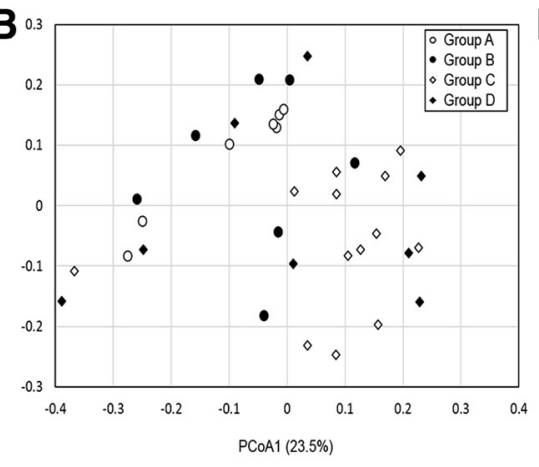

C

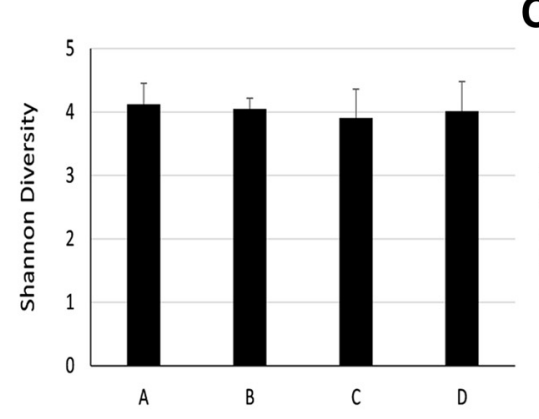

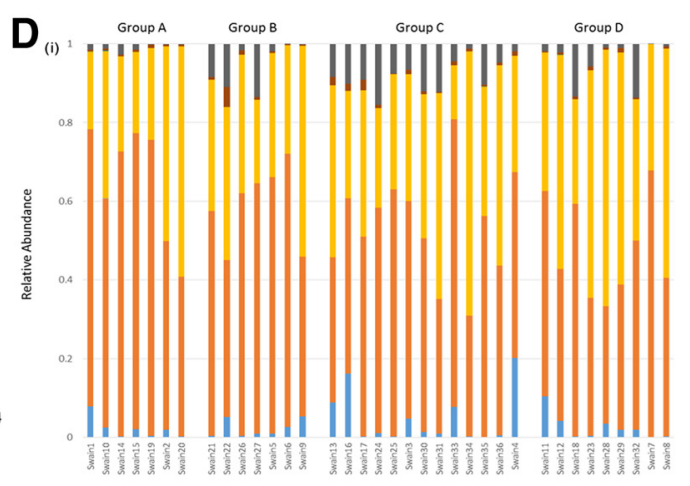

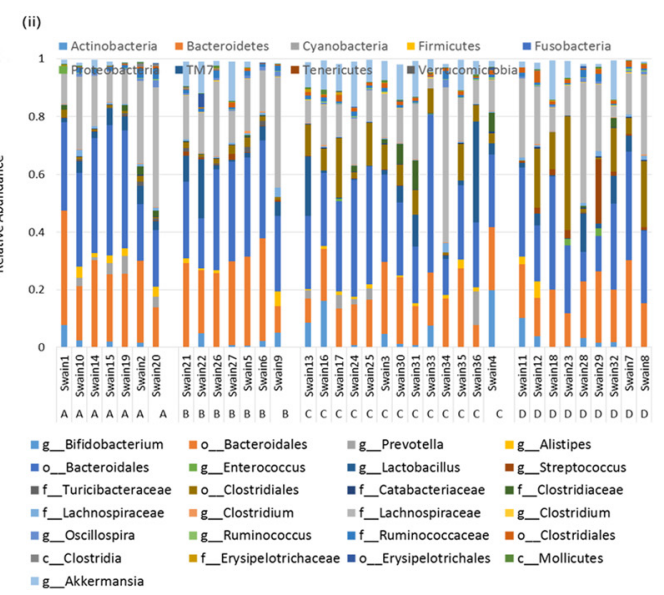

Figure 3. VSL\#3 treatment does not affect the composition of gut microbiota in BDL mice. $A$, Average $\alpha$-diversity measures for each group using Chao1 and Shannon diversity indices. The values were calculated using QIIME with 10 rarefactions to a depth of 10,000 sequences. B. Principal coordinate analysis based on Bray-Curtis distance shows distinct clustering of samples based on whether the mice had undergone BDL, but no distinct separation was observed based on VSL\#3 administration. The axis labels represent the first two principal coordinate axis and the numbers in brackets the percentage variation explained. This separation of groups is supported by the Unweighted Pair Group Method with Arithmetic Mean (UPGMA) tree of weighted UniFrac distance with jackknife support (data not shown). C, Taxonomic summary at the phyla level for each of the four treatment groups. D, Taxonomic profiles of fecal pellets for each mice. The data are presented at the phyla level (i) and highest resolved taxonomic level for the 25 most abundant groups (ii) for each of the four treatment groups. Taxa summaries are indicated as being resolved to the class ( $C$ ) order (0), family (f), or genus (g) level where indicated. Groups in $\boldsymbol{C}$ and $\boldsymbol{D}$ are as follows: $\boldsymbol{A}$, sham placebo; $\boldsymbol{B}$, sham VSL\#3; $\boldsymbol{C}$, BDL placebo; $\boldsymbol{D}, \mathrm{BDL}$ VSL\#3.

Table 2. Plasma levels of cytokines as determined using a Luminex assay

\begin{tabular}{lcccc}
\hline Cytokine & Sham placebo & \multicolumn{1}{l}{ BDL placebo } & Sham VSL\#3 & \multicolumn{1}{l}{ BDL VSL\#3 } \\
\hline Eotaxin & $874.5 \pm 196.2$ & $1588.4 \pm 160.2^{*}$ & $753.1 \pm 226.6$ & $1356.8 \pm 185^{*}$ \\
IL-6 & $4.7 \pm 43.1$ & $206.8 \pm 38^{*}$ & $3.7 \pm 46.6$ & $218.2 \pm 43.1^{*}$ \\
IP-10 & $111.9 \pm 45.5$ & $371.2 \pm 39.4^{*}$ & $121.2 \pm 55.8$ & $339.6 \pm 48.3^{*}$ \\
KC & $46.9 \pm 31.9$ & $201.7 \pm 24.4^{*}$ & $42.1 \pm 34.5$ & $252.7 \pm 29.9^{*}$ \\
MIG & $57.3 \pm 44.6$ & $249.2 \pm 35.6^{*}$ & $83.6 \pm 44.6$ & $153.4 \pm 41.7$ \\
\hline
\end{tabular}

No significant difference was found between the BDL placebo and BDL VSL\#3 groups. Data are shown as mean \pm SEM, $n=6-8 /$ group.

${ }^{*} p<0.05$ versus sham.

signaling, we treated BDL mice with VSL\#3 and etanercept. We found that BDL mice treated with both VSL\#3 and etanercept were similar to BDL-VSL\#3 vehicle-treated mice with regard to the time spent being immobile (BDL-VSL\#3-etanercept: $194.6 \pm$ $32.6 \mathrm{~s}$ vs BDL-VSL\#3-vehicle: $185.4 \pm 42 \mathrm{~s}$ ) or engaged in social exploration (BDL-VSL\#3-etanercept: $241.6 \pm 50.8$ s vs BDLVSL\#3-vehicle: $249 \pm 33.1 \mathrm{~s}$ ).

VSL\#3 treatment reduces microglial activation in BDL mice Oral VSL\#3 treatment significantly reduces elevations of circulating TNF- $\alpha$ levels documented in BDL mice. Therefore, to determine whether this reduction in circulating TNF- $\alpha$ levels is linked to changes in microglial activation within the brain in VSL\#3treated BDL mice, we performed immunohistochemistry for ionized calcium-binding adapter molecule (Iba)- $1^{+}$microglia (Ahmed et al., 2007) in brain sections from VSL\#3- and placebo- treated BDL mice. We observed that microglia in placebo-treated BDL mice exhibited a morphology typical of activated microglia (i.e., were more rounded in appearance with retracted and thicker processes), whereas microglia in VSL\#3-treated BDL mice demonstrated a "resting" morphology (Fig. 5A). We next isolated cerebral mononuclear cells and characterized them by flow cytometry to quantify the number of microglia that were activated in placebo- and VSL\#3-treated BDL mice. Resting microglia were identified as $\mathrm{CD} 11 \mathrm{~b}^{+} \mathrm{CD} 45^{\text {low }}$-expressing cells, whereas activated microglia were identified as $\mathrm{CD}_{11 \mathrm{~b}}{ }^{+}$ CD45 ${ }^{\text {intermediate }}$-expressing cells, as described previously (Sedgwick et al., 1991). VSL\#3 treatment significantly reduced the number of activated microglia isolated from brains of BDL mice (surgery $\times$ treatment: $F=8.34, p=0.01$; Fig. $5 B$ ). In addition, the number of TNF- $\alpha$ expressing microglia in BDL mice was also significantly reduced by VSL\#3 treatment (surgery $\times$ treatment: $F=13.59, p=0.001$; Fig. $5 C$ ). Furthermore, we also investigated the number of activated microglia in BDL mice treated with both etanercept and VSL\#3. We found similar numbers of activated microglia in VSL\#3-treated BDL mice administered etanercept $(1154 \pm 187$ cells/brain) compared with those treated with vehicle (1416 \pm 272 cells/brain).

VSL\#3 treatment reduces leukocyte:CEC adhesive interactions and monocyte infiltration into the brain in BDL mice

We used intravital microscopy to examine leukocyte:CEC interactions within the cerebral vasculature. To do this, cortical blood vessels were visualized through a small cranial window using a 


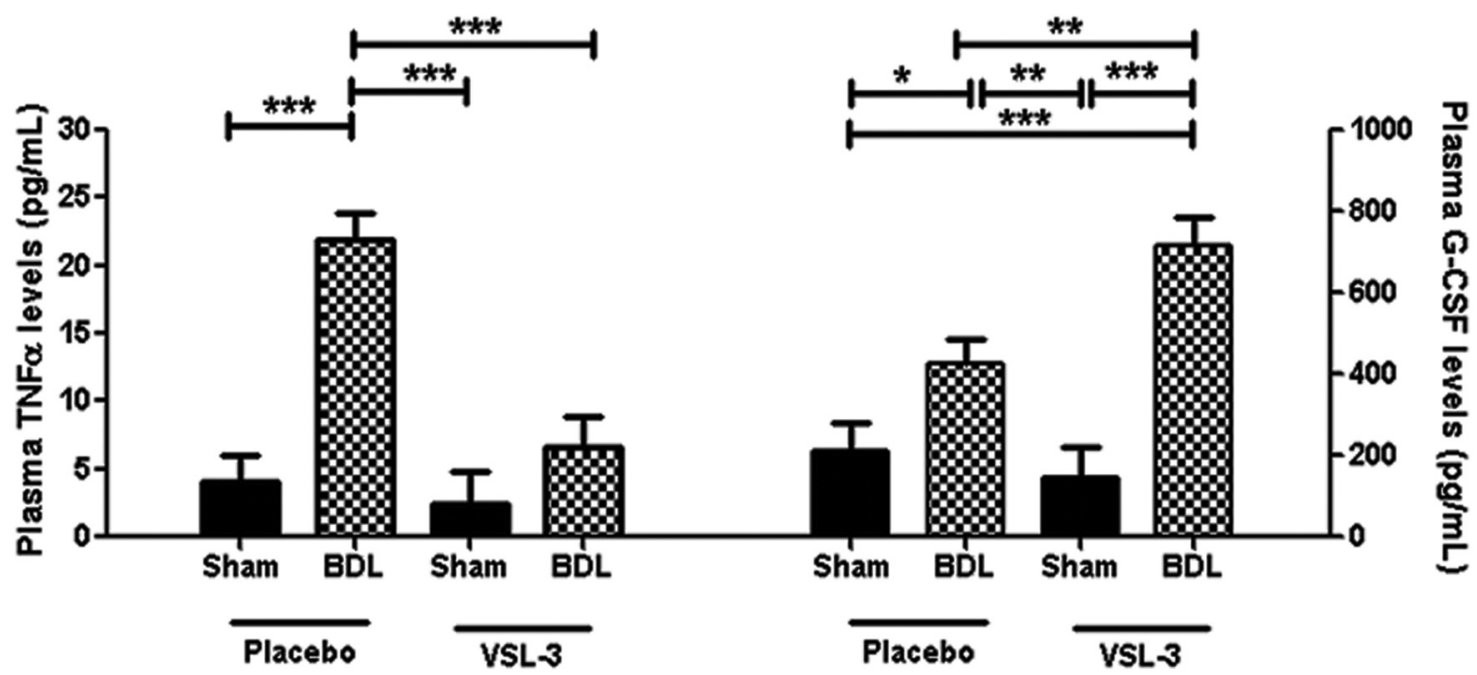

Figure 4. VSL\#3 treatment reduces circulating TNF- $\alpha$ levels in BDL mice. Plasma TNF- $\alpha$ and G-CSF levels as determined using Luminex technology for placebo- or VSL\#3-treated sham and BDL mice. All data are represented as mean $\pm \mathrm{SEM}, n=6-8 /$ group, ${ }^{*} p<0.05,{ }^{* *} p<0.01,{ }^{* * *} p<0.001$.

A
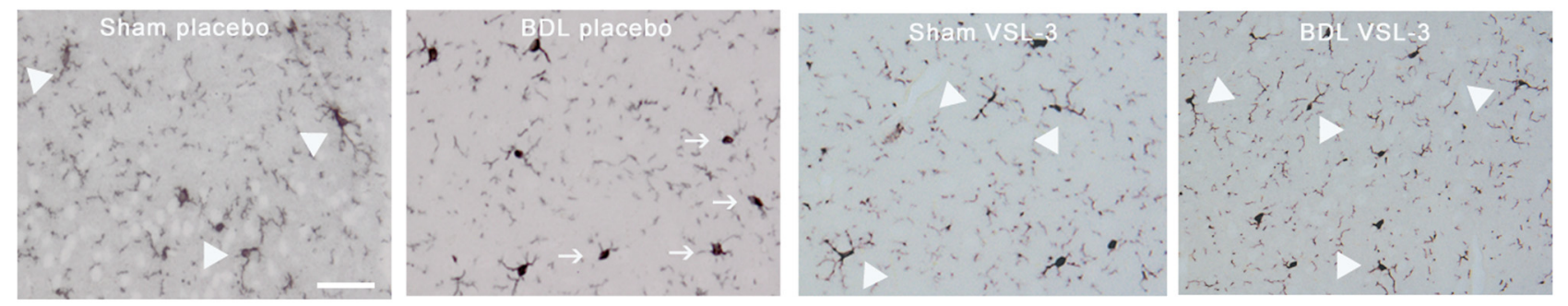

B
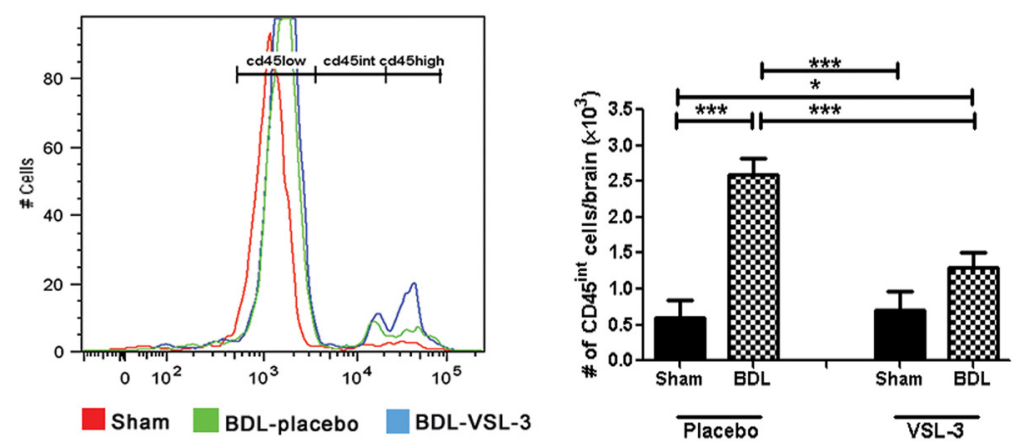

C

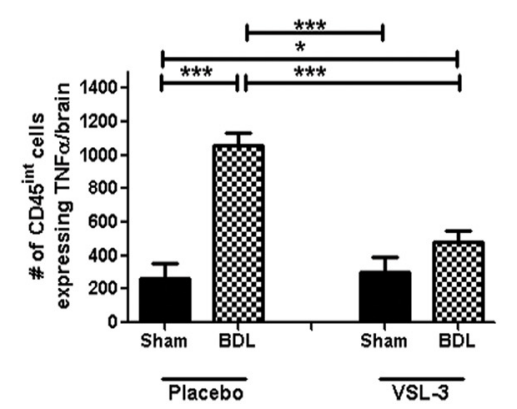

Figure 5. VSL\#3 treatment attenuates microglial activation in BDL mice. A, Representative images from brain sections depicting Iba- ${ }^{+}{ }^{+}$microglia in cortical region of placebo- and VSL\#3-treated

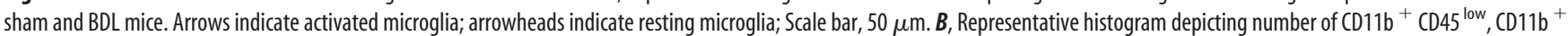
CD45 intermediate, and CD11b ${ }^{+}$CD45 ${ }^{\text {high }}$ cells in sham-, BDL placebo-, and BDL VSL\#3-treated mice. Bar graph indicates number of activated microglia (CD11 ${ }^{+}$CD45 ${ }^{\text {intermediate }}$ cells) as isolated from cerebral cortices of placebo- and VSL\#3-treated sham and BDL mice and characterized using flow cytometry. C, Number of activated microglia (CD11b ${ }^{+}$CD45 ${ }^{\text {intermediate }}$ cells) isolated from cerebral cortices of placebo- and VSL\#3-treated sham and BDL mice that expressed TNF- $\alpha$. All data represented as mean \pm SEM, $n=5-8 /$ group, ${ }^{*} p<0.05,{ }^{* *} p<0.01$, ${ }^{* * *} p<0.001$. int, Intermediate.

spinning disk confocal microscope as described previously (Kerfoot et al., 2006). Mice were administered rhodamine-6G dye (to label circulating leukocytes) and CECs were labeled with an antiCD31 antibody (D'Mello et al., 2013). We documented a striking increase in the number of leukocytes rolling (surgery effect: $F=$ $143.74, p<0.0001$ ) and adherent (surgery effect: $F=10.35, p=$ 0.005 ) along CECs in BDL mice (Fig. 6A-C). However, VSL\#3 treatment in BDL mice significantly reduced the number of leukocytes that rolled (surgery $\times$ treatment: $F=5.5, p=0.03$ ) or were adherent (surgery $\times$ treatment: $F=6.1, p=0.02$ ) to CECs compared with placebo-treated BDL mice (Fig. $6 A-C$ ). To determine whether the reduction in leukocyte:CEC adhesive interactions translated into reduced numbers of monocytes trans- migrating into the brain, we isolated cerebral mononuclear cells and characterized them by flow cytometry. We found that VSL\#3 treatment significantly reduced the number of monocytes (i.e., $\mathrm{CD} 11 \mathrm{~b}^{+} \mathrm{CD} 45^{\text {high }}$ cells) that infiltrated the brains of BDL mice compared with placebo-treated BDL mice (surgery $\times$ treatment: $F=6.86, p=0.016$; Fig. $6 D, E)$. Moreover, the number of TNF$\alpha$-expressing monocytes infiltrating the brain of BDL mice was also significantly reduced by VSL\#3 treatment (surgery $\times$ treatment: $F=7.49, p=0.013$; Fig. $6 F$ ). Furthermore, we also found similar numbers of cerebral infiltrating monocytes in BDL mice treated with both etanercept and VSL\#3 [VSL\#3-treated BDL mice administered etanercept $(1250 \pm 180$ cells/brain $)$ vs those treated with vehicle (1091 \pm 180 cells/brain $)]$. 
A
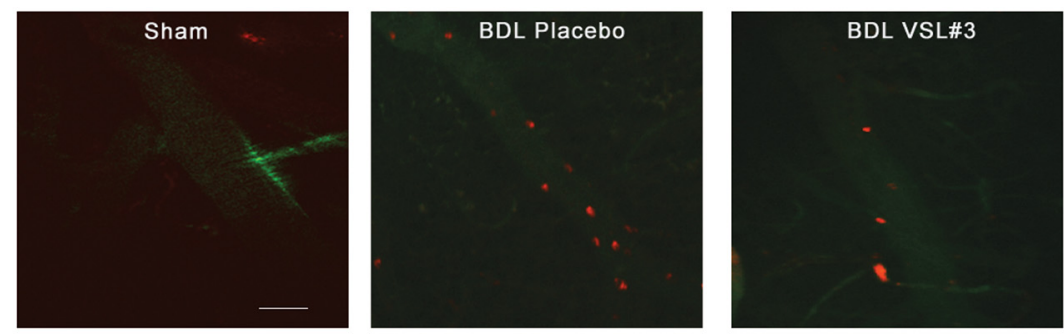

B

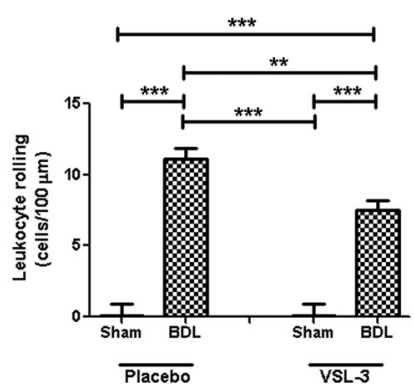

D

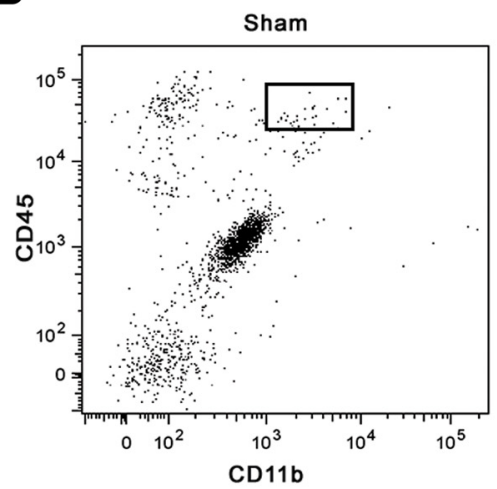

E

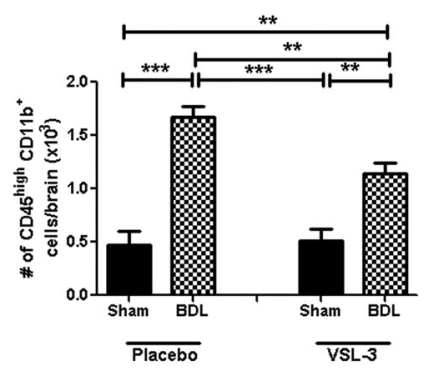

C

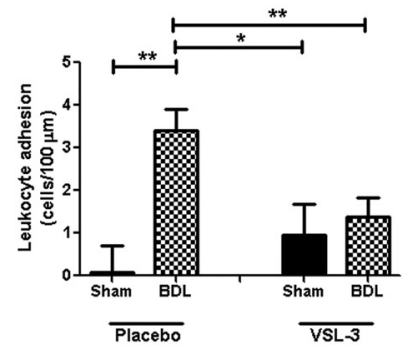

$\mathbf{F}$

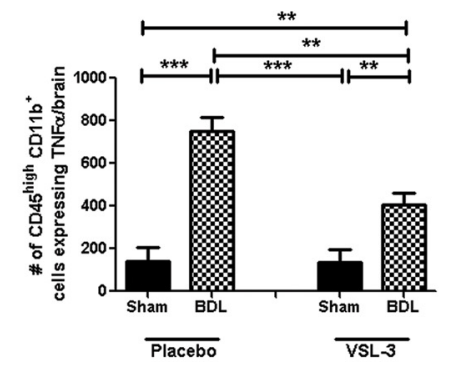

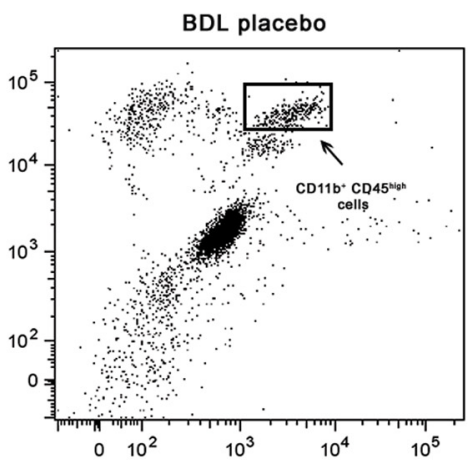

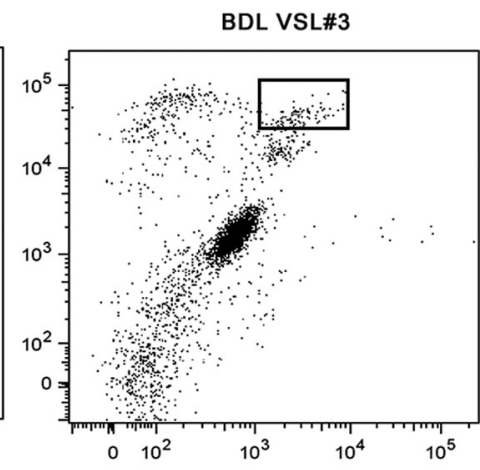

Figure 6. VSL\#3 treatment reduces monocyte:CEC adhesive interactions and monocyte infiltration into brain in BDL. A, Representative images of cerebral vasculature in sham-, placebo-, and VSL\#3-treated BDL mice. Circulating leukocytes were labeled with rhodamine (red); CECs were labeled with FITC anti-CD31 (green). Bar graph indicates number of rolling leukocytes (cells/min/100 $\mu \mathrm{m} ; \boldsymbol{B}$ ) and adherent leukocytes (cells/100 $\mu \mathrm{m} ; \boldsymbol{C}$ ) along CECs in placebo- and VSL\#3-treated sham and BDL mice. $\boldsymbol{D}$, Representative flow cytometry profiles from sham placebo, BDL placebo, and BDL VSL\#3 mice. $\boldsymbol{E}$, Total number of $C D 11 b^{+}$CD $45{ }^{\text {high }}$ cells as isolated from cerebral cortices of placebo- and VSL\#3-treated sham and BDL mice and characterized using flow cytometry. $\boldsymbol{F}$, Total number of CD11b ${ }^{+} \mathrm{CD} 45$ high cells isolated from cerebral cortices of placebo- and VSL\#3-treated sham and BDL mice that expressed TNF- $\alpha$. All data represented as mean \pm SEM, $n=5-8 /$ group, ${ }^{*} p<0.05,{ }^{* *} p<0.01,{ }^{* * *} p<0.001$.

\section{Discussion}

Patients with inflammatory diseases involving peripheral organs or tissues commonly experience altered brain function giving rise to symptoms that adversely affect their QOL (D'Mello and Swain, 2014). How peripheral inflammation leads to remote changes in brain function remains unclear and, as a result, there are limited therapeutic options available clinically to address this issue. A number of general pathways have been described that link systemic inflammation to changes occurring in the brain, which in turn give rise to altered behavior (Dantzer et al., 2014). These pathways traditionally have included signaling via neural pathways (mainly vagal nerve afferents) and immune signaling (mainly via circulating cytokines, which either enter the brain directly or activate cerebral endothelium; Capuron and Miller, 2011). Recently, we described a novel peripheral signaling pathway occurring in the setting of liver inflammation, which involves increased peripheral TNF- $\alpha$ production driving increased microglial activation, followed by monocyte recruitment into brain vasculature and brain parenchyma, which in turn drives the development of sickness behaviors (D'Mello et al., 2013). 
The beneficial effect of probiotic consumption on behavior and brain function is now becoming increasingly appreciated in a variety of inflammatory diseases. Specifically, probiotic administration improves QOL in patients with irritable bowel syndrome (O'Mahony et al., 2005) and was associated with significant improvements in cognitive function and the restoration of impaired hippocampal long-term potentiation in a model of diabetes (Davari et al., 2013). In addition, probiotic treatment in patients with rheumatoid arthritis led to an improvement in symptoms and daily functioning (Mandel et al., 2010; Pineda et al., 2011). Our current data further support a role for probiotics in altering brain function during peripheral inflammation. Specifically, treatment with the probiotic mixture VSL\#3 significantly improved sickness behaviors in mice with liver inflammation. This effect was independent of changes in the severity of liver injury, indicating that the reduction in sickness behaviors seen with VSL\#3 treatment was not due to changes in liver inflammation. Interestingly, and consistent with observations by others (Michail and Kenche, 2011), VSL\#3 treatment did not significantly alter the gut microbiota, suggesting that the effects of VSL\#3 on behavior are independent of overt changes in the gut microbiome.

Potential peripheral pathways that link probiotic ingestion to changes in brain function have primarily focused on the role of vagal afferent nerve signaling and changes in cerebral levels of neuromodulators such as brain-derived neurotrophic factor (Bercik et al., 2010). We now define an alternate signaling pathway established in the setting of liver inflammation, which links probiotic consumption to changes within the brain and alterations in behavior. In patients with inflammatory disease and in animal models of systemic inflammation, VSL\#3 ingestion has been previously shown by others to reduce circulating TNF- $\alpha$ levels (Loguercio et al., 2005; Dhiman et al., 2014; Sánchez et al., 2015; Vaghef-Mehrabany et al., 2014). In addition, VSL\#3 treatment-induced reductions in circulating TNF- $\alpha$ levels were associated with improved neuropsychiatric outcomes, as seen in patients with chronic liver disease (Dhiman et al., 2014). Our current findings in BDL mice parallel these clinical observations and are consistent with our previous studies demonstrating a critical role for elevated levels of TNF- $\alpha$ in the circulation of BDL mice driving sickness behavior development (D'Mello et al., 2009; D'Mello et al., 2013). TNF- $\alpha$-associated sickness behaviors in BDL mice are linked directly to cerebral microglial activation and recruitment of monocytes into the brain vasculature and brain parenchyma (D'Mello et al., 2009; D'Mello et al., 2013). In addition, we have also made similar observations of increased leukocyte recruitment to brain vasculature in a model of inflammatory bowel disease (D'Mello et al., 2009). Our current findings are consistent with a role of VSL\#3 ingestion in disrupting this signaling pathway in BDL mice. Furthermore, TNF- $\alpha$ blockade using etanercept in VSL\#3-treated BDL mice did not further improve sickness behavior development, microglial activation, or cerebral monocyte infiltration in VSL\#3-treated BDL mice, consistent with the VSL\#3 effects in BDL mice being TNF- $\alpha$ related. Interestingly, although VSL\#3 treatment reduced circulating TNF- $\alpha$ levels in BDL mice to sham levels, sickness behavior development was not completely abrogated by VSL\#3 treatment. This finding suggests that alternative signaling pathways must also exist in BDL mice to cause sickness behaviors, possibly those driven by vagal afferent signaling to the brain (Capuron and Miller, 2011).

Changes in cross-talk among the intestinal epithelium, the intestinal immune system, and gut microbes has increasingly been recognized for its capacity to modulate systemic immunity
(Belkaid and Naik, 2013). As a result, probiotics have been administered in an attempt to beneficially alter systemic immunity. Consistent with this paradigm, administration of Bifidobacterium infantis to patients with irritable bowel syndrome was associated with an improvement in symptoms and a normalization of the IL-10 to IL-12 cytokine ratio in peripheral blood mononuclear cells (O’Mahony et al., 2005). Furthermore, probiotic treatment has been shown to reduce circulating levels of systemic proinflammatory biomarkers, including TNF- $\alpha$ levels, in patients with a range of systemic inflammatory conditions including psoriasis (Groeger et al., 2013), rheumatoid arthritis (Vaghef-Mehrabany et al., 2014), chronic fatigue syndrome, and liver disease (Loguercio et al., 2005; Dhiman et al., 2014); all findings replicated in our study. However, it remains unclear how oral VSL\#3 treatment leads to changes in systemic immunity and circulating TNF- $\alpha$ levels. Probiotic administration has been reported previously to induce increased intestinal production of the cytokine G-CSF (Martins et al., 2009). In our current study, consistent with this previous report, we found a striking increase in plasma G-CSF levels in VSL\#3-treated BDL mice compared with placebo-treated BDL and sham mice. G-CSF can affect a wide variety of biological functions that are potentially relevant to our current experimental observations in VSL3\#-treated BDL mice. Specifically, G-CSF significantly attenuates monocyte/macrophage production of TNF- $\alpha$ (Nishiki et al., 2004). Furthermore, G-CSF can mediate a reduction in cerebral inflammation (Nishiki et al., 2004). In BDL mice, monocyte/macrophage production of TNF- $\alpha$ is significantly enhanced compared with sham controls (Kerfoot et al., 2006; D'Mello et al., 2009). Therefore, increased plasma G-CSF levels in BDL mice treated with VSL\#3 may contribute to the reduced circulating TNF- $\alpha$ levels observed in these mice and warrants future investigation.

Together, our data define a novel pathway whereby VSL\#3 ingestion prevents peripheral inflammation-associated increases in circulating TNF- $\alpha$ levels, cerebral microglial activation, and recruitment of activated monocytes into the brain, ultimately attenuating BDL-associated sickness behavior development. Therefore, probiotic therapy may have a therapeutic role in regulating peripheral inflammation-associated brain dysfunction and behavioral alterations that often significantly affect patient QOL.

\section{References}

Ahmed N, Sechi LA, Megraud F, Hasnain SE (2009) A randomized, doubleblind, placebo-controlled pilot study of a probiotic in emotional symptoms of chronic fatigue syndrome. Gut Pathog 1:6. CrossRef Medline

Ahmed Z, Shaw G, Sharma VP, Yang C, McGowan E, Dickson DW (2007) Actin-binding Proteins Coronin-1a and IBA-1 are effective microglial markers for immunohistochemistry. J Histochem Cytochem 55:687-700. CrossRef Medline

Belkaid Y, Naik S (2013) Compartmentalized and systemic control of tissue immunity by commensals. Nat Immunol 14:646-653. CrossRef Medline

Bercik P, Verdu EF, Foster JA, Macri J, Potter M, Huang X, Malinowski P, Jackson W, Blennerhassett P, Neufeld KA, Lu J, Khan WI, CorthesyTheulaz I, Cherbut C, Bergonzelli GE, Collins SM (2010) Chronic gastrointestinal inflammation induces anxiety-like behavior and alters central nervous system biochemistry in mice. Gastroenterology 139: 2102-2112.e1. CrossRef Medline

Bluthé RM, Kelley KW, Dantzer R (2006) Effects of insulin-like growth factor-I on cytokine-induced sickness behavior in mice. Brain Behav Immun 20:57-63. Medline

Capuron L, Miller AH (2011) Immune system to brain signaling: neuropsychopharmacological implications. Pharmacol Ther 130:226-238. CrossRef Medline

Dantzer R, O’Connor JC, Freund GG, Johnson RW, Kelley KW (2008) 
From inflammation to sickness and depression: when the immune system subjugates the brain. Nat Rev Neurosci 9:46-56. CrossRef Medline

Dantzer R, Heijnen CJ, Kavelaars A, Laye S, Capuron L (2014) The neuroimmune basis of fatigue. Trends Neurosci 37:39-46. CrossRef Medline

Davari S, Talaei SA, Alaei H, Salami M (2013) Probiotics treatment improves diabetes-induced impairment of synaptic activity and cognitive function: behavioral and electrophysiological proofs for microbiomegut-brain axis. Neuroscience 240:287-296. CrossRef Medline

De Palma G, Collins SM, Bercik P (2014) The microbiota-gut-brain axis in functional gastrointestinal disorders. Gut Microbes 5:419-429. CrossRef Medline

Dhiman RK, Rana B, Agrawal S, Garg A, Chopra M, Thumburu KK, Khattri A, Malhotra S, Duseja A, Chawla YK (2014) Probiotic VSL\#3 reduces liver disease severity and hospitalization in patients with cirrhosis: a randomized controlled trial. Gastroenterology 147:1327-1337.e3. CrossRef Medline

Distrutti E, O’Reilly JA, McDonald C, Cipriani S, Renga B, Lynch MA, Fiorucci S (2014) Modulation of intestinal microbiota by the probiotic VSL\#3 resets brain gene expression and ameliorates the age-related deficit in LTP. PLoS One 9:e106503. CrossRef Medline

D’Mello C, Swain MG (2014) Liver-brain interactions in inflammatory liver diseases: implications for fatigue and mood disorders. Brain Behav Immun 35:9-20. CrossRef Medline

D’Mello C, Le T, Swain MG (2009) Cerebral microglia recruit monocytes into the brain in response to tumor necrosis factor $\alpha$ signaling during peripheral organ inflammation. J Neurosci 29:2089-2102. CrossRef Medline

D’Mello C, Riazi K, Le T, Stevens KM, Wang A, McKay DM, Pittman QJ, Swain MG (2013) P-selectin-mediated monocyte-cerebral endothelium adhesive interactions link peripheral organ inflammation to sickness behaviors. J Neurosci 33:14878-14888. CrossRef Medline

Groeger D, O'Mahony L, Murphy EF, Bourke JF, Dinan TG, Kiely B, Shanahan F, Quigley EM (2013) Bifidobacterium infantis 35624 modulates host inflamamtory processes beyond the gut. Gut Microbes 4:325-339. CrossRef Medline

Hemarajata P, Versalovic J (2013) Effects of probiotics on gut microbiota: mechanisms of intestinal immunodulation and neuromodulation. Therap Adv Gastroenterol 6:39-51. Medline

Hungin AP, Mulligan C, Pot B, Whorwell P, Agréus L, Fracasso P, Lionis C, Mendive J, Philippart de Foy JM, Rubin G, Winchester C, de Wit N; European Society for Primary Care Gastroenterology (2013) Systematic review: probiotics in the management of lower gastrointestinal symptoms in clinical practice-an evidence based international guide. Aliment Pharmacol Ther 38:864-886. CrossRef Medline

Kerfoot SM, D’Mello C, Nguyen H, Ajuebor MN, Kubes P, Le T, Swain MG (2006) TNF- $\alpha$ secreting monocytes are recruited into the brains of cholestatic mice. Hepatology 43:154-162. CrossRef Medline

Lichtenstein GR, Bala M, Han C, DeWoody K, Schaible T (2002) Infliximab improves quality of life in patients with Crohn's disease. Inflamm Bowel Dis 8:237-243. CrossRef Medline

Loguercio C, Federico A, Tuccillo C, Terracciano F, D’Auria MV, De-Simone C, Del Vecchio Blanco C (2005) Beneficial effects of a probiotic VSL\#3 on parameters of liver dysfunction in chronic liver diseases. J Clin Gastroenterol 39:540-543. CrossRef Medline

Lunia MK, Sharma BC, Sharma P, Sachdeva S, Srivastava S (2014) Probiotics prevent hepatic encephalopathy in patients with cirrhosis: a randomized controlled trial. Clin Gastroenterol Hepatol 12:1003-1008.e1. CrossRef Medline

Mandel DR, Eichas K, Holmes J (2010) Bacillus coagulans: a viable adjunct therapy for relieving symptoms of rheumatoid arthritis according to a randomized, controlled trial. BMC Complement Altern Med 10:1. CrossRef Medline

Martins AJ, Colquhoun P, Reid G, Kim SO (2009) Reduced expression of basal and probiotic-inducible G-CSF in intestinal mononuclear cells is associated with inflammatory bowel disease. Inflamm Bowel Dis 15:515525. CrossRef Medline

Messaoudi M, Lalonde R, Violle N, Javelot H, Desor D, Nejdi A, Bisson JF, Rougeot C, Pichelin M, Cazaubiel M, Cazaubiel JM (2011) Assessment of psychotropic-like properties of a probiotic formulation (Lactobacillus helveticus R0052 and Bifidobacterium longum R0175) in rats and human subjects. Br J Nutr 105:755-764. CrossRef Medline

Michail S, Kenche H (2011) Gut microbiota is not modified by randomized, double-blind, placebo-controlled trial of VSL\#3 in diarrhea-predominant irritable bowel syndrome. Probiotics Antimicrob Proteins 3:1-7. CrossRef Medline

Mittal VV, Sharma BC, Sharma P, Sarin SK (2011) A randomized controlled trial comparing lactulose, probiotics, and L-ornithine L-aspartate in treatment of minimal hepatic encephalopathy. Eur J Gastroenterol Hepatol 23:725-732. CrossRef Medline

Nguyen H, Wang H, Le T, Ho W, Sharkey KA, Swain MG (2008) Downregulated hypothalamic 5-HT3 receptor expression and enhanced 5HT3 receptor antagonist mediated improvement in fatigue like behavior in cholestatic rats. Neurogastroenterol Motil 20:228-235. Medline

Nguyen K, D’Mello C, Le T, Urbanski S, Swain MG (2012) Regulatory T cells suppress sickness behaviour development without altering liver injury in cholestatic mice. J Hepatol 56:626-631. CrossRef Medline

Nishiki S, Hato F, Kamata N, Sakamoto E, Hasegawa T, Kimura-Eto A, Hino M, Kitagawa S (2004) Selective activation of STAT3 in human monocytes stimulated by G-CSF: implication in inhibition of LPS-induced TNF- $\alpha$ production. Am J Physiol Cell Physiol 286:C1302-C1311. CrossRef Medline

O'Connor JC, André C, Wang Y, Lawson MA, Szegedi SS, Lestage J, Castanon N, Kelley KW, Dantzer R (2009) Interferon- $\gamma$ and tumor necrosis factor- $\alpha$ mediate the upregulation of indoleamine 2,3-dioxygenase and the induction of depressive-like behavior in mice in response to bacillus Calmette-Guerin. J Neurosci 29:4200-4209. CrossRef Medline

O’Mahony L, McCarthy J, Kelly P, Hurley G, Luo F, Chen K, O'Sullivan GC, Kiely B, Collins JK, Shanahan F, Quigley EM (2005) Lactobacillus and Bifidobacterium in irritable bowel syndrome: symptom responses and relationship to cytokine profiles. Gastroenterology 128:541-551. CrossRef Medline

Pineda MdLA, Thompson SF, Summers K, de-Leon F, Pope J, Reid G (2011) A randomized, double-blinded, placebo-controlled pilot study of probiotics in active rheumatoid arthritis. Med Sci Monitor 17:CR347-R354. Medline

Sánchez E, Nieto JC, Boullosa A, Vidal S, Sancho FJ, Rossi G, Sancho-Bru P, Oms R, Mirelis B, Juárez C, Guarner C, Soriano G (2015) VSL\#3 probiotic treatment decreases bacterial translocation in rats with carbon tetrachloride-induced cirrhosis. Liver Int 35:735-745. Medline

Sedgwick JD, Schwender S, Imrich H, Dörries R, Butcher GW, ter Meulen V (1991) Isolation and direct characterization of resident microglial cells from the normal and inflamed central nervous system. Proc Natl Acad Sci U S A 88:7438-7442. CrossRef Medline

Strand V, Smolen JS, van Vollenhoven RF, Mease P, Burmester GR, Hiepe F, Khanna D, Nikaï E, Coteur G, Schiff M (2011) Certolizumab pegol plus methotrexate provides broad relief from the burden of rheumatoid arthritis: analysis of patient-reported outcomes from the RAPID 2 trial. Ann Rheum Dis 70:996-1002. CrossRef Medline

Strand V, Burmester GR, Ogale S, Devenport J, John A, Emery P (2012) Improvements in health-related quality of life after treatment with tocilizumab in patients with rheumatoid arthritis refractory to tumour necrosis factor inhibitors: results from the 24-week randomized controlled RADIATE study. Rheumatology 51:1860-1869. CrossRef Medline

Tillisch K, Labus J, Kilpatrick L, Jiang Z, Stains J, Ebrat B, Guyonnet D, Legrain-Raspaud S, Trotin B, Naliboff B, Mayer EA (2013) Consumption of fermented milk product with probiotic modulates brain activity. Gastroenterology 144:1394-1401, 1401.e1-4. CrossRef Medline

Vaghef-Mehrabany E, Alipour B, Homayouni-Rad A, Sharif S-K, AsshariJafarabadi M, Zavvari S (2014) Probiotic supplementation improves inflammatory status in patients with rheumatoid arthritis Nutrition 30 : 430-435. CrossRef

Wang A, Keita $\AA$ V, Phan V, McKay CM, Schoultz I, Lee J, Murphy MP, Fernando M, Ronaghan N, Balce D, Yates R, Dicay M, Beck PL, MacNaughton WK, Söderholm JD, McKay DM (2014) Targeting mitochondria-derived reactive oxygen species to reduce epithelial barrier dysfunction and colitis. Am J Pathol 184:2516-2527. CrossRef Medline

Weiler-Normann C, Schramm C, Quaas A, Wiegard C, Glaubke C, Pannicke N, Möller S, Lohse AW (2013) Infliximab as a rescue treatment in difficult to treat autoimmune hepatitis. J Hepatol 58:529-534. CrossRef Medline

Whelan FJ, Verschoor CP, Stearns JC, Rossi L, Luinstra K, Loeb M, Smieja M, Johnstone J, Michael G, Surette MG, Bowdish DM (2014) The loss of topography in the microbial communities of the upper respiratory tract in the elderly. Ann Am Thorac Soc 11:513-521. CrossRef Medline 